\title{
SACRu Și Profan în OICONImie. ASpecte etimologice
}

\author{
Nicolae Felecan \\ Universitatea Tehnică Cluj-Napoca; \\ Centrul Universitar Nord, Baia Mare, România
}

\section{Sacred and profane in oikonymy. Etymological aspects}

\begin{abstract}
This paper aims at highlighting the reasons which, in certain times, led to the elimination of oikonyms based on religious and profane names. From the former category, we will only pay attention to names derived from appellatives in religious language, such as biserica 'the church', călugărul 'the monk', călugăra 'the nun', cruce 'cross', diacon 'deacon', episcopia 'the bishopric', mănăstirea 'the monastery', mitropolia 'the metropolis', popa 'the priest', rai 'heaven', schitu 'the skete' etc. As regards the latter category, we will take into consideration names with demeaning or indecent connotations. From this viewpoint, several subcategories of names will be defined, as in time the connection with the initial meaning has been lost and the form of the oikonym has become different from that of the etymon. Eloquent examples in this respect are Beșa, Beșeneu (etymologically 'Pecheneg', literally 'to fart'), Coita (lit. 'bollock'), Fătăciune (lit. 'litter (of animals)'), Flocești (lit. 'pubic hair'), Gaura (lit. 'the hole'), Iad (etymologically 'hunting', lit. 'hell'), Omor (lit. 'murder'), Poponeți (lit. 'bums'), Spurcați (lit. 'impure'), Tâmpești (lit. 'to become stupid'), Tonți (lit. 'stupid') and others.
\end{abstract}

Keywords: anthroponymy, oikonymy, onomastics, sacred, profane, terminology, diachrony.

\section{Introducere}

Înainte de a trece la dezvoltarea problemei propuse, se cuvine a face câteva precizări legate de noțiunile sacru și profan. Conform DEX, sacru are semnificațiile: „1. Cu caracter religios; privitor la religie, care aparține religiei; Sfânt. 2. (fig.) Care inspiră sentimente de venerație; scump. - din lat. sacer, -cra, it. sacro" (DEX, s. v.). Și Dicționarul enciclopedic se menține în acești parametri: „sacru este un adjectiv din latină sau italiană, având sensurile: 1. Ceea ce posedă forță sau energie supranaturală (Dumnezeu) și care provoacă deopotrivă în om sentimente de teamă și fascinație, de respingere și atracție. Cu caracter religios; sfânt. 2. (fig.) Care inspiră sentimente de venerație; divinizat, venerat” (DE, s.v.).

Având ca punct de plecare sacrul, indiferent de forma sub care apare, profanul se plasează la polul opus: „1. care este ignorant într-un domeniu oarecare; neștiutor, nepriceput, ageamiu. 2. Care nu ține de religie, care nu reprezintă sau nu exprimă un punct de vedere religios; laic. 3. Care nu respectă lucrurile considerate sacre; necredincios. - din fr. profane, lat. profanus” (DEX, s. v.; cf. și DE, s. v.). 
Structura și semnificația cuvântului în latină, din pro + fanum ,în afara templului” (Guțu 1983, s. v.), ne arată, indubitabil, de ce termenul se situează la polul opus sacrului: pro, aici element de compunere, cu sensul „înainte, în afara”, și fanum „loc consacrat solemn de către pontifice unei divinități; lăcaș sfânt, sanctuar, templu" (Guțu 1983, s. v.).

\section{Surse de documentare și abordare teoretică}

În demersul nostru ne-am folosit de lucrări scrise (Tezaurul toponimic al României - Moldova, Muntenia, Banat, Transilvania -, Indicatorul localităților din România), și online: Localități din România cu nume schimbat, Localități cu nume haioase (ro.wikipedia. org/wiki/).

\section{Localități cu nume sacre}

În țara noastră numărul localităților cu nume sacre era (și mai este încă) destul de mare. Acestea au apărut, cum preciza Iorgu Iordan „din timpul orânduirii feudale, când, la fel ca în alte țări, viața spirituală era stăpânită de biserică” (1963: 232).

Referitor la accepțiunile termenului oferite de cele două dicționare, credem că în conceptul de sacru trebuie să admitem trei nivele lexicale - primul se referă la Dumnezeu și ceea ce implică direct divinitatea, al doilea trimite la sfinții care și-au închinat viața slujirii lui Dumnezeu, iar al treilea conține apelativele care, prin semnificația lor, au legătură, direct sau indirect, cu ceea ce este venerat, sfânt, adică cu religia.

Ca urmare, şi etimologia denumirilor conduce la trei categorii de nume: legate de divinitate, de sfinți și de apelative ce denumesc stări clericale, lăcaşuri de cult ori noțiuni religioase în sens larg. În lucrarea de faţă ne propunem să urmărim, pe baza materialului excerptat, măsura în care toate aceste denumiri se încadrează, cu adevărat, în sfera sacrului sau dacă nu este cumva și un joc al hazardului, al unor fenomene lexicale - omonimii, paronimii, sinonimii ori chiar al unor etimologii populare - nesesizate de cei care au contribuit la înlocuirea lor.

Mai întâi, pentru ușurarea înțelegerii, vom grupa denumirile schimbate, incluse în Indicatorul localităților din România, în categoriile impuse de etimon:

- oiconime biblice ori în legătură cu funcții și simboluri creștine (concrete ori abstracte): Bădeni-Miluiți (Câmpeni, jud. Buzău) ${ }^{1}$, Bodești-Țintirim (jud. Buzău), Crucea (Vâlcelele, jud. Ialomița), Crucile (Gruița, jud. Dolj), Iad (Livezile, jud. BistrițaNăsăud), Iuda (Viile Tecii, jud. Bistrița-Năsăud), Miluiți (Valea Sălciilor, jud. Buzău), Mureș-Mort (Lunca Mureșului, jud. Mureș), Odaia Protopopului (Satu Nou, jud. Ilfov), Raiu-Blândești (Blândești, acum înglobat în satul Țigănași, jud. Iași). Acestea trimit la persoane biblice, Iuda, ori la apelativele cruce, iad, milui, moarte, protopop, rai, țintirim;

- oiconime legate de viața monahală: Călugăra (Măgura, jud. Bacău), Călugări (Ponoarele, jud. Bihor; Scărişoara, jud. Buzău), Călugărița (Glâmbocata-Deal, jud. Argeș; Merișani, jud. Teleorman; Negrești, jud. Neamț), Călugăru (Cetatea, jud. Gorj;

\footnotetext{
1 Între paranteze am dat numele nou și județul din care fac parte.
} 
Stejaru, jud. Ilfov; Măgura, jud. Teleorman), Protosinghelu (Lazu, jud. Prahova). Toate acestea trimit la apelativele călugăr, călugăra (formă de feminin mai veche), călugăriță (forma actuală de feminin), protosinghel ;

- oiconime legate de lăcașuri de cult, biserică, mănăstire, schit: Biserica (Făgetu de Sus, jud. Bacău; Lăcustenii de Sus, jud. Vâlcea), Mănăstirea (Mînăstioara, jud. Dâmbovița), Schitu (Dealul Frumos, jud. Buzău; Ceahlău, jud. Neamț);

- oiconime legate de circumscripții administrative în fruntea cărora se află un ierarh, episcopie, mitropolie: Băbiciu Episcopiei (Băbiciu, jud. Olt), Episcopia (Gușoianca, jud. Vâlcea), Mitropolia (Tufanu, înglobat la satul Tîncăbești, jud. Ilfov, Clănița, jud. Teleorman);

- oiconime cu trimitere la Fecioara Maria și la Fiul Ei, Isus Cristos: Precista (Ceahlăul, jud. Neamț); Slobozia ${ }^{3}$ Pruncului ${ }^{4}$ (Slobozia Sucevei, jud. Suceava). În situații determinate, duc la aceste personaje și apelativele: precista, adj. „Curată (din punct de vedere moral), neprihănită, imaculată; (substantivat) Maica Domnului, Fecioara Maria”. - Din sl. prečista (DEX, s. v.); prunc, s. m. 1. (înv. și pop.) copil (indiferent de vârstă sau sex); (sens curent) copil în primele luni de viață. 2. (înv. și reg.) copil în raport cu părinții săi; fiu. - Et. nec." (DEX, s. v.). Cu litere mari, se referă la Isus Cristos.

Schimbarea numelor de acest fel s-a produs, cu precădere, în timpul regimului comunist, instalat în România după cel de-al Doilea Război Mondial, care n-a putut accepta denumiri cu tentă religioasă. Totuși, în ciuda acestui fapt, au mai rămas asemenea oiconime, fie că regimul de la București nu le cunoștea, fie cănu era interesat să producă prea multe nemulțumiri în rândul populației. Alte argumente în acest sens aduce O. Felecan (2017: 81): „On the one hand, a likely explanation could be the fact that Romanians represented the minority in those settlements. On the other hand, such omissions may be explained by the achievement of the target to change most religious names. In other words, the aim was not to eliminate religion from the oikonymic landscape, but to take it out of the spotlight".

Etimologic vorbind, fiecare oiconim din cele menționate se referă la un apelativ transparent, astfel încât, la prima vedere, lucrurile sunt clare. Unele dintre ele, precum biserică, cimitir, cruce, mănăstire, morminte etc., trimit la urme materiale, „din care se mai păstrează ruine ${ }^{5}$, cum arată descrierile, adesea amănunțite și interesante, care se dau în Marele Dicționar Geografic al României” (Iordan 1963: 232). Altele, ca episcopie,

2 Protosinghel, s. m. „grad monahal superior singhelului și inferior arhimandritului; monah care are acest grad" (DEX, s.v.).

3 Slobozie, s. f. (înv.) Sat de coloniști (băștinași sau străini) care aveau pe o perioadă oarecare scutire de bir sau de prestații. Din slobod + suf. -ie. (DEX, s. v.). Situația Sloboziilor a fost amplu analizată de Iorgu Iordan, în Toponimia românească, p. 198-204.

4 După hramul mănăstirii căreia îi aparținea.

5 Existența acestor ruine poate fi motivată de faptul, precizat de Iorgu Iordan astfel: „își părăseau țăranii satele de baștină, spre a se stabili aiurea sau a trece chiar granița, în speranța că vor găsi acolo condiții de viață mai omenească. Satele astfel părăsite se distrugeau cu vremea, 
mitropolie, trimit la noțiuni abstracte: „locurile numite astfel au fost ori sunt încă proprietatea instituțiilor al căror nume îl poartă” (cf. Iordan 1963: 236).

Noi ne-am oprit asupra acelora care, prin etimonul atribuit, nu justifică legătura cu semnificatul. În această situație se află câteva oiconime dispersate în întreaga țară:

Iad, sat în jud. Bistrița-Năsăud, cu nume schimbat în 1964 în Livezile. Primele referiri asupra denumirii le găsim la Nicolae Iorga, în însemnările de călătorie prin Ardeal și Banat, unde amintește că, părăsind Bistrița, „valea bătută de vânt duce întâi la Altdorf, căruia ai noștri îi zic Aldrof sau, mai pe scurt, Aldru... Mai departe e Iadul. Numele trebuie să-i fie românesc, dar acest 'iad' nu seamănă deloc cu iadul fioros care așteaptă pe vinovații lumii acesteia" (Iorga 1977 II: 53)6.

Iorgu Iordan amintește, alături de Iad „sat” (jud. Bistrița-Năsăud) ${ }^{7}$ și Iad „vale” (jud. Argeș), Capul Iadului și Gura Iadului (jud. Buzău), Valea Iadului (afluent al Crişului Repede; jud. Bihor). În privința etimologiei are rețineri, din moment ce face afirmația: „despre satul bistrițean aflăm de la Kisch I, p. 301 că numirea se justifică prin poziția locului ('în timpul așezării slavilor acolo regiunea li s-a părut ca un iad'), iar Gura Iadului se cheamă niște izvoare cu apă minerală, al căror miros de sulf a determinat pe oameni să le boteze astfel” (Iordan 1963: 248-249, cf. Kisch 1929: 301).

DTR Muntenia alătură numelor menționate de Iorgu Iordan și altele, astfel încât lista completă pentru această zonă este: Capul Iadului și Gura Iadului (Ploiești), „Iadu<vale > or. Mioveni - Argeș, Iadu<culme muntoasă> or. Nehoiu - Buzău, Iadu Negurii<loc $>$ or. Predeal - Braşov" (DTR Muntenia, s. v.).

Noi credem că trebuie separat oiconimul Iad de celelalte denumiri care trimit la toponime minore. În primul rând dorim să menționăm faptul că localitatea la care ne referim este atestată la 1311, cu numele Iaad, apoi în variantele Jad 1331, villa Jad, plebanus de Venaciene 1332, sacerdos de Venatione 1334 (Suciu I: 361, s. v. Livezile).

Fiind un sat săsesc, așezat într-o zonă cu o populație majoritar săsească, având ca centru orașul Bistrița, considerăm că etimologia numelui se află în cuvântul săsesc Iaad/Jad/Jagd „vânătoare”, și nu are nimic cu locul în care „sufletele păcătoșilor sunt supuse la chinuri veșnice pentru a-și ispăși păcatele din timpul vieții; infern” (DE, s. v.). Însuși Iorga, la începutul secolului al XX-lea, când a făcut călătoria prin Ardeal și Banat, se referea la discrepanța dintre denumirea iad și natura locului (cf. citatul de mai sus).

Perimetrul în care a apărut localitatea era înconjurat de numeroase păduri, cu mare potențial de vânătoare. Prin urmare, considerăm că termenul săsesc indică suficient de bine o situație economică (o ocupație), care a putut da numele localității. De altfel, chiar la anul 1332 găsim precizarea villa Jad, plebanus de Venaciene, iar la 1334 sacerdos de Venatione, ceea ce ar putea însemna că satul era cunoscut și cu denumirea

dar rămâneau bisericile, adică ruinele lor, care rezistau la intemperii, grație relativei solidități a construcției” (1963: 232).

6 Cf. N. Iorga, Pagini alese din însemnările de călătorie prin Ardeal și Banat, vol. 2, București: Editura Minerva, 1977.

7 Între paranteze am trecut județele după configurația actuală.

8 Cf. www.primarialivezilebn.ro/cadrul demografic 
Venatio,vânătoare” (cf. lat. venatio, -onis, s. f. „vânătoare”: multum sunt in venationibus (Caesar) „se ocupă mult cu vânătoarea”;Guțu, 1983, s. v.), având și atribuții de apărare. În acest sens putem menționa o mulțime de localități, situate pe întreg cuprinsul țării, a căror denumirese leagă nu numai de acest aspect, ci și de armată, prin „arma nouă a vânătorilor"9: Vânătorești (jud. Satu Mare), Vânători (jud. Arad, Botoșani, Cluj, Constanța, Galați, Iași, Ilfov, Mehedinți, Mureș, Teleorman, Vrancea), Vânători-Neamț (jud. Neamț), Vânătorii Mari, Vânătorii Mici (jud. Ilfov) (cf. Indicatorul, 1974, s. v.).

Forma Iad a apărut la 1733 și s-a menținut în variantele Iadul, Iadu, Iad, alături de cele săsești Iaad, Jadu, Iadt, Jaadt până în 1964, când autoritățile comuniste, necunoscătoare ale originii și semnificației cuvântului, au schimbat numele în Livezile ${ }^{10}$ (Suciu I, s.v.).

În ce ne privește, nu credem că etimologia legată de iad „infern” este potrivită, fiindcă, în acest caz, ar trebui să avem mai multe localități denumite astfel.

Localitatea în cauză se afla într-o zonă locuită de sași, nu de români. Și cine ar putea da un nume localității, în afară de localnicii înșiși sau de locuitorii satelor din jur, cu toții sași, care au pentru iad (= infern) denumirea Hölle.

Ca urmare, considerăm că etimonul oiconimului este săsescul Iaad / Jad / Jagt „vânătoare”, cuvânt cu o grafie apropiată și o pronunție identică cu cea din română.

Alta este situația toponimelor minore considerate a avea același etimon. Dacă pentru numele localității, Iorgu Iordan preia afirmația lui Gustav Kiss, pentru Gura Iadului face precizarea că numele îi vine de la „izvoarele cu apă minerală, al căror miros de sulf a determinat pe oameni să le boteze astfel”. Vedem în această afirmație o apropiere de simbolistica iadului, reprezentat ca un „infern de foc, duhnind a pucioasă”, care iese la suprafață prin „gurile iadului (înfățișate asemenea celor ale dragonilor)” (Biedermann 2002: 193).

În privința celorlalte accepțiuni ale denumirii Iad, prezente în DTR Muntenia, „vale” (Argeș); „culme muntoasă” (Buzău); „loc” (Brașov), ele trebuie interpretate ca provenind de la un antroponim, numele proprietarului sau o poreclă a acestuia.

O altă localitate cu nume controversat este Iuda, tot în jud. Bistrița-Năsăud, devenită, după anul 1964, Viile Tecii. Ea este atestată de la 1332 „poss. Ida, sacerdos de Yda”, iar la 1334, Joda. La 1670 apare denumirea maghiară, Nagj Ida, cu varianta Nagy Ida, apoi, la 1733 Juda, la 1750 Iuda, la 1760-1762 Nagy Ida, la 1850 Iuda Mare, iar la 1854 în trei limbi: Nagy Ida, Eida, Iuda Mare (cf. Suciu II: 247, s. v. Viile Tecii).

De fapt, este tot o denumire săsească, Ida, Jöda, Aide, germ. Großeidau, Grosseidau, Eyda ${ }^{11}$, magh. Nagyida, Kolozsnagyida (cf. Suciu II: 247), ajunsă în română omonimă cu numele personajului biblic, cum afirmă Iorgu Iordan: „cred că-i vorba de Iuda, apostolul despre care Biblia povestește că a trădat pe Isus” (Iordan 1963: 242, s. v.). Totuși,

9 Cf. Iordan 1963: 218: „locuitorii satului nemțean Vînători aveau obligații militare și constituiau un fel de garnizoană a curții domnești, după modelul de apărare a orașelor săsești din Ardeal. ... Erau totodată datori să vâneze pentru domnul țării”.

10 Cf. Decretul nr. 799 din 17 decembrie 1964.

11 https://ro.wikipedia.org/wiki/Viile_Tecii,_Bistri\%C8\%9Ba-N\%C4\%83s\%C4\%83ud 
acelaşi autor, Iorgu Iordan, menționând forma compusă Iuda Mare, atestată la 1850, precizează: „Iuda Mare (Bis.) provine, prin etimologie populară, din Ida Mare (= magh. Nagyida). Poate la fel se va fi explicând și Iuda (Bis)" (Iordan 1963: 242, nota 4).

Așadar, etimonul trebuie legat de cuvintele săsești Ida, Jöda, Aide, care, printr-un joc paronimic, au ajuns ușor la forma $I u d a$, cu trimitere, fie la numele personajului biblic, fie la o poreclă, devenită antroponim pentru cineva dovedit ca trădător, șiret, ipocrit.

Ca toponim, în Muntenia, Iuda apare de 14 ori singur, cu semnificațiile: „coastă

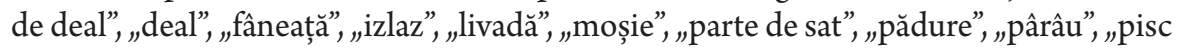
muntos”, „plai”, „poiană, „râpă”, „vale”, „vâlcea”, „vârf”, unele cu mai multe apariții, şi de cinci ori cu determinant toponimic: Iuda Mare, Iuda Mică (în jud. Dâmbovița și Prahova), cu accepțiunile „pădure”, „plai”, „vâlcea”, „vârf”, pentru care DTR Muntenia trimite la apelativul iudă „grămadă de arbori răsturnați”, „vânt puternic” (DTRM, vol. $3: 235$, s. v. Iuda $a^{1}$.

Un alt oiconim care a împărtășit aceeași soartă a înlocuirii este Miluiţi. Indicatorul localităților din România menționează două localități din județul Buzău cu acest nume, dar care au dispărut; un sat a fost înglobat la Câmpeni, com. Amaru, iar celălalt a primit denumirea de Valea Sălciilor, com. Tisău (Indicatorul 1974, s. v.).

Iorgu Iordan, pomenind aceste două sate, dintre care unul cu patru subdiviziuni - Miluiții propriu-zis, Miluiții-Barbu, Miluiții-Ciolanul și Miluiții-Moșneni - și două toponime, Miluiții-Barbu „pădure”, Bădeni-Miluiți („foste moșii”) ${ }^{12}$, trage concluzia că „miluiți ar fi sinonim cu 'robi', aşadar cu 'țigani', pe baza faptului „că Barbu și Ciolanul sunt mănăstiri” (1963: 324), ale căror moșii erau lucrate cu robi, fie români, fie țigani. În ceea ce privește Miluiții-Moșneni, autorul afirmă că „numele Miluiți, dat la început numai satului ori satelor cu robi, se va fi extins, cu timpul, și la un sat vecin, locuit de moșneni”'13 (Iordan 1963: 324, nota 4).

Ca urmare, Iorgu Iordan a inclus acest oiconim în capitolul IV „Psihologice” și nu în capitolul II, $\mathbb{S} 12$ „Toponimice care vorbesc despre credințe, superstiții și obiceiuri”, bazându-se pe înțelesul de „rob” al adjectivului miluit și nu pe cel religios: „darnic, milostiv".

O interpretare în afara sacrului există și pentru oiconimele Rai(ul) (jud. Bacău, Botoșani, Iași, Vaslui), Raiul Saşilor (jud. Prahova), Răiuțul (jud. Vrancea). Iorgu Iordan afirmă că „Existența unor astfel de nume se poate explica în mai multe chipuri. După concepția populară curentă, trebuie să ne gândim, înainte de toate, la un loc 'frumos', nu numai din punct de vedere estetic, ci și, cu deosebire, economic, aşadar, la o regiune fertilă și îmbelșugată”, așa cum se menționează și pentru alte regiuni europene - Cehia,

12 D. Frunzescu, Dicționarul Topografic și Statistic al României, București, 1872, notează o „moșie nelocuită” cu acest nume și în Râmnicu Sărat, cf. Iordan 1963: 324, nota 3.

13 Moșnean, moșneni, s. m. 1. (în orânduirea feudală) Țăran liber din Țara Românească, posesor în devălmășie al unei proprietăți de pământ moștenite de la un străbun comun; moștean, răzeș. 2. (înv.) Moștenitor, successor. 3. (înv. și reg.) Băștinaș (DEX, s. v.). 
Croaţia, Germania, Italia ${ }^{14}$. O altă idee are în vedere „un loc situat la o înălțime relativ mare, aproape, deci, de Dumnezeu”, explicație care „s-ar potrivi, poate, pentru muntele Răiuţiu (jud. Vrancea), care întrece, în altitudine, spune DG, toți munții de pe teritoriul comunei Mera şi, într-o măsură mai redusă, pentru satul Raiul (jud. Iaşi), aşezat pe o coastă de deal, în fața satului Blîndești, de care-l desparte Valea Blîndeștilor. Acest ultim toponimic ne duce cu mintea la o altă interpretare posibilă. Deoarece blind este sinonim cu blajin, iar blajin, ca termen religios, înseamnă răposat (cf. Paştile Blajinilor 'Lunea de după Duminica Tomei, când femeile duc la cimitir cozonac și ouă roșii pentru sufletele morților'), putem presupune că satul vecin a fost numit Raiul pornindu-se de la astfel de sugestii"15 (Iordan 1963: 249-250).

Așadar, schimbarea denumirii acestor localități a avut la bază criterii formale, fapt ce i-a permis lui Dragoș Moldovanu să afirme că „toponimia oficială este, în mare parte, o creație cu vădit caracter artificial, care ignoră raportul de motivare între semnul lingvistic și referent (localitate desemnată)" (1991: LII).

\section{Oiconime profane}

O situație asemănătoare ne întâmpină şi în cazul oiconimelor profane. Schimbarea acestora are ca punct de pornire, în general, sensul negativ - injurios, indecent ori denigrator - al apelativului care stă la baza denumirii. Până în prezent, multe dintre ele au format obiectul unor studii, precum Toponimie românească și internațională, de Ion Nicolae și Bogdan Suditu (2008), Change of Names in $20^{\text {th }}$ Century Romanian Toponymy, de Domnița Tomescu (2012: 353-364), Oiconime "decretate". Aspecte sociolingvistice, de Nicolae Felecan (2015: 478-487), Oiconime "decretate”: Aspecte sociolingvistice II, de Oliviu Felecan, Nicolae Felecan (2015: 131-143), Un veac de transformări oiconimice in România (2016: 439-453) și Oikonymic Transformations in Romania in the Second Half of the Twentieth Century (2017: 78-87), de Oliviu Felecan.

Dar, și aici sunt situații care ignoră raportul de motivare. În cele ce urmează ne vom referi la alte situații decât cele menționate în lucrările anterioare.

Se știe că toponimia românească a moștenit destule denumiri vechi, care trimit la fapte istorice. Între acestea se află și denumirea unor popoare migratoare. Amintim aici numele pecenegilor (în scrierile latinești bessi), „populație migratoare de neam turcic, originară din Asia Centrală, care s-a așezat la sfârșitul sec. 9 în Moldova, apoi în Țara Românească, Dobrogea și Transilvania în calitate de aliați ai țarului bulgar Simion. În sec. 11 au fost înfrânți de uzi, fiind asimilați treptat de populația autohtonă” (DE, s. v.). Documentele menționează un privilegiu de la 1224 al regilor unguri pentru coloniștii

14 ZONF III: 74-75; ZONF XI: 157; Archivio Glottologico Italiano XXIV, sezione neolatina, p. 37, unde sunt menționate toponimele Paradis (dalm.), Raj (croat.) existente în ins. Veglia; Germanoslavica IV: 67, unde sunt menționate toponimele cehe Ràjov, Rajitse, Rajšitse (cf. Iordan 1963: 249).

15 D. Pușchilă, în An. Geogr. și Antropogeogr. II: 158, crede că numele aici în discuție păstrează sensul secundar de „livadă”, pe care v. slav. raj îl avea alături de cel principal (cf. Iordan 1963: 250, nota 2). 
germani aduși în Transilvania „spre a da un nou avânt exploatării bogățiilor miniere, meșteșugurilor și comerțului”, constând din „pădurea românilor și pecenegilor” (sylva Blacorum et Bissenorum) cu apele care o străbat, spre a se folosi de ea în comun, cu zișii români și pecenegi” (Giurescu 1971: 195). La 1432 se menționează „vinee in monte Bessenew alias Heydendorff, duo ingera vinearum in Heydendorff" ${ }^{16}$, care aparțineau satului Paganika, atestat la 1332 (plebanus de Villa Paganika ${ }^{17}$, Villa Paganika), numit în 1750 Beșineu, iar la 1760-1762 Bessenyö (cuvânt maghiar cu același înțeles „pecenegi”, și, la 1850 Bessenyö, Heydendorff, Beșineu (cf. Suciu 1968: 247, s. v. Viişoara).

Indicatorul localităților din România nu amintește de acest nume, dar consemnează alte sate cu nume asemănătoare: Beșeneu, veche denumire a satului Moacşa, com. Moacșa, jud. Covasna; Beșenova (Veche), veche denumire a satului Dudeștii Vechi, com. Dudeștii Vechi, jud. Timiș; Beșenova Nouă, veche denumire a satului Dudeștii Noi, com. Becicherecu Mic, jud. Timiş̧; Beșimbac ${ }^{18}$, veche denumire a satului Olteț, com. Viștea, jud. Braşov; Beşinău, veche denumire a satului Secășel, com. Ohaba, jud. Alba; Beșineu, veche denumire a satului Valea Izvoarelor, com. Sînpaul, jud. Mureș.

Aceste sate, afirmă Vasile Frățilă, se află pe „liniile de prisăci create pentru apărarea granițelor teritoriilor cucerite" (2011: 15) de către maghiari în expansiunea de ocupare a teritoriilor românești ${ }^{19}$, fiindcă „paza și apărarea prisăcilor ca și a punctelor de trecere prin ele (aşa-numitele porți, în magh. kapú) nu erau făcute de maghiari, ci de alte populații: de secui și pecenegi” (Frățilă 2011: 15).

În cazul denumirii Beșenova avem a face cu numele slavizat, atestat sub forma Beschenova, la 1723-1725, înainte acesta fiind numit Beseneu (1213), Beșeneu, Besentu (1230) (Suciu 1967: 212), în care se recunoaște magh. besen „peceneg” (Frăţilă 2011: $186)$.

Faptul că astăzi nu mai există sate cu această denumire se datorează, în primul rând, faptului că numele, în atestările menționate, a fost apropiat, prin etimologie populară, de un cuvânt considerat, în epoca comunistă și chiar astăzi în viziunea unor vorbitori, ca necuviincios.

În același mod au dispărut și alte oiconime care porneau de la ocupații tradiționale, precum creșterea animalelor, mari sau mici, dintre care numele unora nu se cuvenea a fi puse în legătură cu persoana umană. Între acestea amintim: Bivolița

16 Franz Zimmermann, Urkundenbuch zur Geschichte der Deutschen in Siebenbürgen, IV 478,482 .

17 Numele Paganika dovedește că locuitorii, pecenegii, erau „păgâni”, iar „Traducerea săsească a unor nume de-ale satelor pecenege din Ardeal (Hêndraf< < Hêndrof = „Heidengorf”, alături de Betschanûden) ne arată că ei existau încă neasimilați de români și de cumani, chiar și la venirea saşilor" (Drăganu 1933: 514).

18 Beșimbac, din magh. Besinbák, săs. Beschenbach (Iordan 1963: 279).

19 „Ardealul a fost ocupat în cinci etape succesive, începând de la nord spre sud: Linia Someșului Mic pe la anul 900, linia Mureșului pe la anul 1000, linia Târnavei Mari pe la anul 1100, linia Oltului pe la anul 1150 și linia Carpaților pe la 1200” (vezi K. Horedt, Contribuții la istoria Transilvaniei sec. IV-XVII, București, 1958: 112; cf. Frăţilă 2011: 15, nota 17. 
(Izvoarele, com. Izvoarele, jud. Teleorman; Bou (Izvorașu, com. Sutești, jud. Vâlcea; Viişoara, com. Păunești, jud. Vrancea); Bou Roș (Izvoarele, com. Corbița, jud. Vrancea); Bouleni (Dealul Pădurii, com. Cotmeana, jud. Argeș); Bouşoru (Stejerelul, înglobat la sat. Măiag, com. Crușeț, jud. Gorj); Scroafa (Stejărel, com. Luncoiu de Jos, jud. Hunedoara); Valea Porcului (Alunișu, com. Băiculești, jud. Argeș; Valea Stejarului, com. Vadu Izei, jud. Maramureș); alte sate $\mathrm{cu}$ asemenea nume au fost desființate.

\section{Concluzii}

În concluzie putem spune că, din motive de ignoranță, datorate, cel mai adesea unor omonimii, paronimii sau etimologii populare, multe denumiri care aminteau de fapte istorice sau de îndeletniciri tradiționale, astăzi uitate, au dispărut. Aceasta înseamnă, desigur, și eliminarea din istorie a unor urme materiale privitoare la devenirea neamului românesc și la privațiunile întâmpinate de-a lungul timpului.

\section{Bibliografie}

Biedermann, H. 2002. Dicționar de simboluri I, II. București: Editura Saeculum I.O.

DE = Dicționar enciclopedic, vol. I-VII. 1993-2006. București: EdituraEnciclopedică.

Decretul nr. 799 din 17 decembrie 1964.

DEX = Dicționarul explicativ al limbii române (DEX). 1975. București: Editura Academiei.

DG $=$ Marele Dicționar Geografic al României. 1898-1902. București.

Drăganu, N. 1933. Românii în veacurile IX-XIV pe baza toponimiei și a onomasticei. București.

DTRM = Dicționarul toponimic al României Muntenia, vol. 1-6. 2005-2015. București: Editura Academiei Române.

Felecan, N. 2015. Oiconime "decretate". Aspecte sociolingvistice. În Proceedings of the Third International Conference on Onomastics "Name and Naming". Conventional / Unconventional in Onomastics, O. Felecan (ed.), 478-487. Cluj-Napoca: Mega, Argonaut.

Felecan, O., N. Felecan. 2015. Oiconime „decretate”: Aspecte sociolingvistice II. În Mioara Avram. In memoriam, S. Pitiriciu (ed.), 131-143. Craiova: Editura Sithec.

Felecan, O. 2016. Un veac de transformări oiconimice în România. În Magistri et alumni, amore scribendi. Studia. In honorem Professoris Nicolae Felecan, O. Felecan, D. Felecan (coord.), 439453. Cluj-Napoca: Mega, Argonaut.

Felecan, O. 2017. Oikonymic Transformations in Romania in the Second Half of the Twentieth Century. Names 65 (2): 78-87.

Frățilă, V. 2011. Studii de toponimie. Cluj-Napoca: Editura Dacia.

Frunzescu, D. 1872. Dicționarul Topografic și Statistic al României. București.

Giurescu, C.C, Dinu C. Giurescu. 1971. Istoria românilor din cele mai vechi timpuri până astăzi. București: Editura Albatros.

Guțu, G. 1983. Dicționar latin - român. București: Editura Științifică și Enciclopedică.

Horedt, K. 1958. Contribuții la istoria Transilvaniei sec. IV-XVII. București.

Iordan, I., P. Gâștescu, D. I. Oancea. 1974. Indicatorul localităţilor din România. București: Editura Academiei.

Iordan, I. 1963. Toponimia românească, București: Editura Academiei.

Iorga, N. 1977. Pagini alese din însemnările de călătorie prin Ardeal și Banat, vol. II. București: Editura Minerva. 
Kisch, G. 1929. Siebenbürgen im Lichte der Sprache. Hermannstadt.

Nicolae, I., B. Suditu. 2008. Toponimie românească și internațională. București: Editura Meronia. Moldovanu, D. 1991. Introducere la Tezaurul Toponimic al României. Moldova, vol. I, Repertoriul istoric al unităților administrativ-teritoriale 1772-1988, Partea I, A Unități simple (Localităţi și moșii), A-O. București: Editura Academiei Române

Suciu, C. 1967-1968. Dicționar istoric al localităților din Transilvania, I, II. București: Editura Academiei.

Tomescu, D. 2012. Change of Names in $20^{\text {th }}$ Century Romanian Toponymy. In Name and Naming: Synchronic and Diachronic Perspectives, O. Felecan (ed.), 353-364. Newcastle upon Tyne: Cambridge Scholars Publishing.

Wikipedia. Viile Tecii, Bistrița-Năsăud. https://ro.wikipedia.org/wiki/Viile_Tecii,_ Bistri\%C8\%9Ba-N\%C4\%83s\%C4\%83ud (accesat în septembrie 2017).

Zimmermann, F. 1937. Urkundenbuch zur Geschichte der Deutschen in Siebenbürgen, vol. I-IV. Sibiu: E. Zimmermann, E. Gündisch Gustav.

ZONF = Zeitschrift für (Orts-)Namenforschung I urm., 1925 urm. München.

www.primarialivezilebn.ro/cadrul demografic 